\title{
A global analysis of the social and environmental outcomes of community forests
}

Reem Hajjar ${ }^{1,2 * a}$, Johan A. Oldekop ${ }^{2,3 * a}$, Peter Cronkleton ${ }^{4}$, Peter Newton ${ }^{2,5}$, Aaron J.M.

Russell ${ }^{6,7}$, Wen Zhou $^{8}$

5

${ }^{1}$ Department of Forest Ecosystems and Society, Oregon State University, OR 97331, USA

${ }^{2}$ Forest and Livelihoods: Assessment Research and Engagement (FLARE) network, School for

Environment and Sustainability, University of Michigan, MI 48109, USA

${ }^{3}$ Global Development Institute, The University of Manchester, M13 9PL, UK

$10 \quad{ }^{4}$ Center for International Forestry Research, La Molina Lima, 15024, Peru

${ }^{5}$ Environmental Studies Program, University of Colorado Boulder, Sustainability, Energy and

Environment Community, Boulder, CO 80309, USA

${ }^{6}$ Center for International Forestry Research, Jalan CIFOR, Situ Gede, Bogor Barat, 16115, Indonesia.

$15{ }^{7}$ Global Green Growth Institute, MONREC Bldg. 53, Naypyitaw, 15011, Myanmar

${ }^{8}$ Yale School of the Environment \& Department of Anthropology, Yale University, New Haven, CT 06511

* both authors contributed equally to this work

20 a To whom correspondence should be addressed. E-mail: reem.hajjar@oregonstate.edu, johan.oldekop@manchester.ac.uk

Keywords: community based natural resource management | forest tenure and resource rights | forest livelihoods | systematic review | decentralization 


\section{A global analysis of the social and environmental outcomes of community forests}

Abstract:

Community forest management (CFM) has been promoted for decades as a way to merge environmental conservation with economic development and natural resource rights agendas. Yet, many of these initiatives have also led to substantial socioeconomic and environmental trade-offs. We present a comprehensive global analysis of environmental, income, and natural resource rights outcomes of CFM, using data from 643 cases in 51 countries. We find that while the majority of cases reported positive environmental and income-related outcomes, forest access and resource rights were often negatively affected by policies to formalize CFM, countering one of CFM's principal goals. Positive outcomes across all three dimensions were rare. We show that biophysical conditions, de facto tenure rights, national context, user group characteristics, and intervention types are key predictors of joint positive outcomes. These findings highlight key conducive conditions for CFM interventions, which can inform CFM design to ensure positive outcomes across multiple sustainability dimensions.

\section{Main text:}

50 Forests regulate climate, sequester and store carbon, harbor a large proportion of terrestrial biodiversity, and contribute directly to livelihoods of millions of people who live in or close to forests $^{1-3}$. The role of forests in achieving sustainability targets has been re-emphasized by national and international sustainability agendas, including the Sustainable Development Goals, the Bonn Challenge, and the Paris Climate Agreement.

Over the past 40 years, community forest management (CFM-where forest users have some role in determining how local forests are to be managed) has been promoted as a way to merge environmental conservation with economic development and natural resource rights agendas. The rationale underpinning this push rests on the premise that local groups, who have vested interests in maintaining forest resource flows, can make better use of place and timespecific information than more centralized forms of forest governance, which can lead to more sustainable practices and improved livelihoods ${ }^{4}$. Currently, approximately $14 \%$ of forests worldwide, and approximately $28 \%$ of forests in low and middle income countries, are formally 
owned or managed by Indigenous peoples and local communities ${ }^{5}$. Yet, while case studies showing that CFM can promote positive outcomes for forests and people abound, many initiatives have led to substantial socioeconomic and environmental trade-offs ${ }^{6-8}$.

Gaining a deeper insight of such trade-offs is critical to advance understanding of the potential for forest governance systems to simultaneously address multiple sustainable development objectives. Recent analyses have sought to assess livelihood and forest outcomes of CFM interventions across a number of case studies or at a national scale ${ }^{9-14}$, but these studies

70 only provide partial understandings of the joint outcomes expected of CFM, with few considering equity outcomes ${ }^{15}$. In particular, none of these studies have evaluated changes in resource rights as an outcome of CFM, but rather have assumed that formalization of CFM will increase community rights as part of the intervention. Other studies point to incidents where formal rights were not implemented in practice, or where devolved formal rights were more restrictive than existing customary or de facto resource rights already in existence ${ }^{6,16,17}$.

Our understanding of these potential trade-offs is currently limited because of a lack of comprehensive global studies that synthesize information on how CFM has contributed to the multiple environmental, livelihood and natural resources rights outcomes it was intended to achieve. We address this knowledge gap by conducting the most comprehensive global analysis of environmental, livelihood, and natural resource rights outcomes of CFM to date. We used data on 643 CFM cases in 51 countries, collated from 267 peer-reviewed studies (from an initial pool of 15,879 ) resulting from a systematic review ${ }^{18,19}$, to assess the frequency of joint positive outcomes and trade-offs, and how different outcome combinations are influenced by various socio-economic and biophysical factors.

\section{Trade-offs in outcomes}

We generated three separate outcome variables, combining reported information on changes in environmental indicators (forest cover, forest condition, and biodiversity), livelihood indicators (community and household income), and resource access rights indicators (commercial access and subsistence access) following CFM interventions (see methods for details). While resource rights are often a structural component of CFM interventions (e.g. devolving harvest or land rights to communities), our goal was to assess whether rights to access resources had indeed increased or decreased for some or all resource users following the intervention. 
We found that CFM predominantly led to mixed results for forests, livelihoods, and 95 rights. Environmental condition improved after CFM in 56\% of the 524 cases tracking environmental condition, and decreased in 32\% of cases. Incomes increased in $68 \%$ of the 316 cases reporting on livelihoods, $26 \%$ showed no change in incomes, and only $6.3 \%$ of cases reported decreases in income. Finally, 34\% of the 249 cases reporting on resource access rights indicated an increase in resource rights after CFM was implemented, 54\% reported decreases in 100 rights, and $12 \%$ reported no change.

This substantial variation in outcomes is mirrored in our assessment of joint outcomes. Of the 186 cases that studied resource rights and forest environmental condition, $45 \%(\mathrm{n}=83)$ reported trade-offs between both outcomes (where one outcome increased and the other decreased), with most trade-offs ( $82 \%$ of these 83 trade-off cases) characterized by increases in

105 environmental conditions and decreases in resource rights (Figure 1a). Reductions in resource rights occurred either for all resource users or for those local people who had been left out of the community of rights holders defined in CFM interventions.

Studies examining income and access rights outcomes $(n=169)$ found both joint increases (34\% of these 169 studies) and trade-offs (31\%) with increases in income associated with 110 decreases in access rights (Figure 1b). In many trade-off cases, forest-based income mostly benefited village elites, while the poor and marginalized (particularly women, youth and minorities) suffered from forest use restrictions implemented as part of formalized management plans $^{20,21}$. In other trade-off cases, individuals participating in newly outlawed activities (e.g. hunting or logging) had their rights curtailed, while others not previously involved in these

115 activities saw benefits from alternative income sources (e.g. NTFP harvesting) or local infrastructure development (e.g. school repairs) ${ }^{22}$. While these cases would have been coded as "increases in income" in our analysis (the study reported that CFM had brought increases in income), we separately recorded whether a study specifically reported on inequities in benefit sharing: $50 \%$ of the 274 cases that reported on benefit-sharing indicated that benefit-sharing had 120 become less equitable following CFM.

Of the 223 cases examining income and forest environmental condition outcomes, $46 \%$ found simultaneous increases in both outcomes (Figure 1c). For example, cases in India and Ethiopia show that community management and livelihood diversification activities improved 
key indicators of forest environmental condition and income from both forest-based and non-

125 forest based income streams ${ }^{23,24}$.

Finally, of 122 studies analyzing three-way outcomes, only $18 \%$ reported positive outcomes across the three dimensions. These were located in India $(n=8)$, Nepal $(n=5)$, Cameroon $(n=4)$, Bolivia $(n=2)$, Burkina Faso $(n=1)$, Philippines $(n=1)$, and Saint Lucia $(n=$ 1). However, when additional livelihood measures are taken into consideration, some of these 130 cases also presented mixed CFM outcomes. For example, community forestry in Cameroon resulted in gains in community rights over local forests, with an improvement in forest condition and generation of community income from the sale of timber, but had yet to show noticeable improvements in living conditions and overall well-being ${ }^{25}$, indicating the need to consider additional livelihood metrics in future assessments. Additional cases reported increases in 135 outcomes across two dimensions, and no change in the third, and thus were not categorized as having positive outcomes across all three dimensions. But a closer examination of some of those cases showed that "no change" was in itself sometimes a desirable outcome. For example, three cases from Mexico reported increases in incomes and forest condition, and no change in rights; but those communities already had substantial subsistence and commercial rights to the forest for 140 decades prior to the particular intervention.

It is worth noting that while our focus is on trade-offs across outcome categories, we also observed trade-offs within categories in a number of cases. For example, we found six cases reporting the expansion of some rights over resources -formally recognizing the existence of local customary rights- while simultaneously restricting other rights, including curtailing 145 commercialization of forest resources or hunting rights. Sixteen cases reported increases in community income (in the form of investments in community development infrastructure, e.g., schools or wells) while individual or household incomes throughout the community decreased, usually from a loss of access to forest products. In terms of environmental outcomes, 17 cases reported increases in forest cover but decreases in forest biodiversity, or vice versa. While these 150 and other conflicting outcome cases only represent $8 \%$ of our sample (and were excluded from the analyses of trade-offs amongst the principal outcome categories of environment, income, and rights presented here, see methods), these conflicting outcomes illustrate the need for closer examination of more nuanced trade-offs within outcome domains. 


\section{Variables associated with double and triple positive outcomes}

We used information from the 643 case studies on 50 contextual variables to identify factors associated with joint double and triple positive outcomes (Figure 2). The 50 variables (Supplementary Table 1) were selected after a detailed literature review ${ }^{18,19}$. Variables encompass biophysical conditions, local and national-level institutions, market factors, usergroup characteristics, and CFM intervention characteristics. Our statistical analysis expands the method developed by Oldekop et al. ${ }^{26}$, and combines multiple imputation of missing data ${ }^{27}$ with variable selection and model averaging to account for the large amount of predictor variables in our statistical models (see methods for details and robustness checks using simulated data). We discuss the five predictor variables, grouped thematically, explaining most of the variation in our models for each combination of outcomes (defined as the partial weighted pseudo $R^{2}$ ).

Biophysical conditions. Forest type was linked to all double and triple positive outcomes (Figure 2), although the type of forest associated with particular joint outcomes was outcome dependent (Figure 3). Joint positive environment and income outcomes were more likely to

170 occur in tropical/sub-tropical montane forests than any other forest types (Figure 3a), positive environment and resource rights outcomes were more likely to occur in tropical/sub-tropical humid and montane forests (Figure 3b), and positive income and resource rights outcomes were more likely to occur in temperate montane forests (Figure 3c). While our results show that positive outcomes across two or three dimensions were more likely to occur in mangrove forests

175 than other forest types, the number of mangrove forest cases in our study was small (9 of the 643 total cases), highlighting a need for further study of community management of mangroves. Elevation was also a key factor in determining joint environment and income outcomes, and joint environment and resource rights outcomes. Forests at low and medium elevations were more strongly associated with positive outcomes than those at high elevations, where incomes are

180 perhaps lessened due to decreased forest productivity ${ }^{28}$ and difficulties in harvesting and transporting forest products to market ${ }^{29}$.

Local and national-level institutions. De facto rights, defined as locally upheld rights regardless of their legal standing, were associated with positive outcomes for all but joint environment and income outcomes. Cases were more likely to report positive outcomes when 
these informal or customary rights over local management decisions existed prior to the intervention (Figure 3 - de facto management rights). Having de facto exclusion rights (the right to decide who has access to the resource) prior to the intervention was also important for double positive outcomes across dimensions, and having de facto management rights prior to the 190 intervention was important for triple positive outcomes. Notably, cases were less likely to see double or triple positive outcomes if the community only had de facto access and withdrawal rights without collective choice rights to make the rules for management (see Schlager and Ostrom $^{30}$ for a typology of resource rights). Lack of exclusion rights can make CFM management rights inoperable ${ }^{8}$; assuming that management entails decisions and actions made

195 with the expectation of future benefits, the lack of assurance that benefits will not be lost to others would discourage management investments. Having only de jure access and withdrawal rights prior to the intervention was associated with positive environment and rights outcomes and income and rights outcomes (Figures 3b,c); this is likely because CFM interventions are often accompanied by an increase in formal rights, so those with a lower baseline of de jure (formal)

200 rights were more likely to record improvements. The relative importance of de facto rights in comparison with de jure rights in our analysis reaffirms studies showing that perceived tenure, as well as customary tenure rights and other informal institutions and their enforcement, are more important conditions than formal property rights for ensuring sustainability ${ }^{31-34}$. The probability of positive joint income and environment outcomes was lower when community members did 205 not adhere to local forest use rules (Figure 3a).

The national-level governance score (an aggregate index of six governance indicators obtained for each country from the World Bank data catalog) was negatively correlated with joint income and resource rights outcomes. Similarly, the Human Development Index score (a composite index of income, education and health dimensions) was negatively correlated with 210 joint environment and income outcomes and triple-win outcomes (Figure 3). This may have been due to changes relative to low baselines prior to the implementation of CFM projects -those starting with low HDI and governance scores may have more readily shown improvements in outcomes.

215 Intervention characteristics. Co-management approaches other than Joint Forest Management (JFM, specific programs and institutional arrangements prevalent in India) and Participatory 
Forest Management (PFM, specific programs prevalent in eastern Africa) were more likely to be associated with positive joint outcomes for environment and income. While JFM and PFM programs can also be considered types of co-management approaches, we distinguish between

220 the specific JFM and PFM country programs that have narrower objectives ${ }^{35}$, and studies that used the term "co-management" to broadly denote a more equitable sharing of power and responsibility between governments and local user groups ${ }^{36}$. Co-management cases performed better than "other" cases. This result perhaps indicates that where both government and local actors are actively engaged in CFM, and where co-management potentially leads to greater

225 access to additional resources (e.g., financial support or extension services), joint environment and income outcomes may result, echoing similar findings in protected area governance ${ }^{26}$. In cases where a CFM policy change had been implemented in addition to the CFM intervention, the length of time since the enactment of the CFM policy seemed to positively influence the achievement of triple outcomes, indicating that improvements following policy changes take

230 time, but might be longer lasting. Targeted interventions in the absence of policy changes were more likely to achieve triple positive outcomes, but we are unable to predict their sustainability. Whether the CFM intervention included commercial timber extraction (an expected income generator and theorized motivator for sustainable practices ${ }^{37,38}$ ) did not emerge as an important predictor of positive joint outcomes.

User-group characteristics. User group characteristics exhibited lower explanatory power in our models than other variables. Echoing other studies ${ }^{39,40}$, we found that smaller user groups were associated with better joint environment and rights outcomes (Figure 3b). Communities with either no migration, or marked outmigration, were more often associated with positive 240 income and rights outcomes, and triple positive outcomes, than communities with marked inmigration (Figures 3c,d). Rural migration to urban areas and other countries is a frequently cited socioeconomic driver of natural reforestation on abandoned agricultural lands ${ }^{41-43}$, and local incomes could increase through remittances ${ }^{44,45}$. With a dwindling population, remaining forest users may also be able to access larger shares of forest benefits and rights. Communities

245 experiencing in-migration were less likely to report win-win outcomes, perhaps because inmigration can lead to further contestation of rights, increased pressure on forest resources, or exacerbate existing inequities ${ }^{46-48}$. Cases with no migration also fared slightly better relative to 
cases with out-migration. This may be due to out-migration's effects on local institutions and traditional practices ${ }^{49}$.

\section{Discussion}

We advance existing scholarship on CFM by analysing its multiple social and environmental outcomes, including changes in resource rights, across different contexts. While previous studies show community-based conservation has resulted in more synergies than trade-offs ${ }^{52}$, our results

255 suggest that CFM initiatives might need to be re-designed to ensure positive outcomes across multiple sustainability dimensions. Our global study significantly expands on the rich literature of individual case studies documenting problems with the devolution of resource rights, including difficulties with the decentralization process itself, the nature of the rights given to communities $^{6,53,54}$, or the translation of legal rights into rights in practice and realized benefits ${ }^{55-}$ $260 \quad 57$.

Outcome trade-offs: rights are often compromised. We show that forest access and resource rights are often negatively affected by new formal CFM arrangements, countering one of the principal goals of CFM. Community forestry is often promoted as a means to recognize de facto

265 community rights, yet our results highlight the need to carefully examine who in local communities benefit from collective rights, who is left out of the creation of new communitybased institutions, and who is negatively affected by changes to individual rights ${ }^{47,58,59}$. Examples from Nepal, Kenya, Cameroon and elsewhere show that the formalization of rights can actually constrain resource access and customary uses ${ }^{54,59}$. In some cases, administrative

270 bottlenecks and burdensome regulations restricted the ability of local people to take advantage of newly devolved rights ${ }^{47,60}$, limiting potential for livelihood improvements. In other cases, communities were often charged with managing degraded forests with little commercial value ${ }^{54}$, providing a possible explanation for positive environmental outcomes: starting conditions were so poor that there was room for quick improvement, and reforms tended to prioritize conservation or restoration ${ }^{16}$. It is possible that these cases represent a trade-off where environmental condition has improved explicitly as a result of decreased access rights (keeping people out of the forest allowed for recovery and regeneration), but causal mechanisms behind such results are difficult to isolate through meta-analyses. 
Trade-offs between rights and income -reflected in many cases by increases in incomes 280 and decreases in rights- were particularly striking, as we expected the two outcomes to be synergistic in improving livelihoods. It is possible that while a CFM intervention may have constrained a community's de facto informal forest rights, having limited but formal rights over some forest products may still result in increased income -individual or communal-due to the ability to legally commercialize those forest products. It is also possible that income increases in

285 these cases were experienced by some while others saw their access to the forest restricted, highlighting distributional asymmetries within communities. A trade-off can be seen in these cases: the formalization of local rights has benefited some in the community by improving their livelihoods, at the expense of others excluded from previously enjoyed access rights. Our results thus suggest that CFM initiatives should pay closer attention to rights in rights-based approaches, 290 not only in devolving rights to communities, but how those rights (and thus benefits) are shared within communities.

Yet, despite rights being compromised in more than half the cases reporting resource rights outcomes (134 of 249 cases), we see that, where rights were increased ( 85 cases), forest condition and income were generally either maintained or enhanced: of the cases that reported 295 increases in rights, 75\% saw improvements or maintenance of forest condition and all saw improvements or no change in incomes. This suggests that even if development and conservation agents are mostly concerned with improving forest condition, or increasing local incomes, a rights-based approach can be an important predictor of positive outcomes for those goals. This is consistent with studies showing that formal recognition of indigenous rights to traditional lands

300 has been associated with reduced deforestation relative to other ownership and management arrangements (for example, ${ }^{61-63}$ ). While our analysis is unable to disentangle true causal links, the strong association between positive rights outcomes and other outcomes (but not the converse) warrants further study using research designs that can specifically isolate the effect of resource rights.

What explains joint outcomes? Our study provides important new insights into the role that biophysical factors and national contexts play in predicting multiple positive outcomes. We also support findings of seminal studies on the importance of community institutions, intervention types, and user group characteristics in predicting positive outcomes (e.g. $\left.{ }^{64,65}\right)$. Notably, no 
310 market factors emerged as important in predicting joint outcomes, although market factors were some of the least reported variables in the CFM literature (Supplementary Figure 3), despite strong theories of change linking markets to land use change ${ }^{50}$ and forest community development ${ }^{51}$. Here we highlight three factors that were particularly important in predicting multiple joint outcomes: biophysical conditions, national context, and tenure rights. Biophysical

315 factors have often been overlooked as predictors of variation in CFM outcomes, or have been omitted in the scholarship on community-based natural resource management ${ }^{52,66,67}$. We show that forest type and elevation were key predictors of double-positive and triple-positive outcomes. Similarly, the interactions between the national governance context and national development trajectories in which CFM interventions take place have been less examined at

320 broad scale. While Brooks et al. ${ }^{52}$ did not find evidence that national context influenced community-based conservation success, we found that low national-level development and governance indicators were more likely to be associated with positive joint outcomes.

Longitudinal analyses, better collection of baseline data and integration of existing datasets, and greater use of causal inference methods ${ }^{68}$ should be a key consideration for future research to

325 examine the interactions among these drivers of decentralization and development, and outcomes of CFM. Lastly, community institutional arrangements, particularly the types of tenure rights communities held prior to the CFM intervention, played an important role in CFM outcomes. Across the different outcomes, our study provides evidence that having de facto management rights prior to the intervention was positively associated with multiple joint outcomes,

330 highlighting the importance of examining how CFM interventions interact with pre-existing resource rights in communities. Our results broadly suggest that CFM interventions have been more successful where strong community institutions already existed prior to the intervention. While having management rights entails a variety of institutional arrangements across cases, with varying degrees of decision-making autonomy ${ }^{17}$, our results support studies linking local

335 participation in decision-making and management to positive social and environmental outcomes $^{11,12,62}$.

We acknowledge the limitations, assumptions and biases associated with meta-analyses and systematic reviews, including i) biases linked to the use of secondary data that are subject to individual authors' research interests and interpretations, include data from various study 340 designs, and may not account for concurrent national trends in development and rights, ii) the 
simplification of information presented in articles to be able to standardize data recording across studies, and iii) the large amounts of missing data and the need for data imputation. However, given the importance of this topic to both conservation and development agendas globally, being able to draw information from existing literature and synthesize lessons learned is critical, and

345 we encourage further studies that make use of existing literature for evidence-based synthesis and action.

Our global study demonstrates the need to understand the conditions under which CFM can accomplish concurrent "wins" across multiple dimensions. The loss of rights, even under well-intentioned policies, has already been documented in a number of case studies. This meta-

350 analysis amplifies those findings for CFM, highlighting that rights are often either traded-off for environmental improvements, or that distributional asymmetries within communities may result in income gains for some but rights losses for others. Policy-makers and development agents may want to consider the best path to achieving positive outcomes for rights, environment, and livelihoods by clarifying their theories of change: should rights be delivered first with the

355 expectation of ensuing income and conservation gains; should interventions focus on conservation priorities and alternative livelihoods with the expectation that community empowerment through devolution of forest rights occur separately; or should all three objectives be included at the policy or project design stage? These decisions would also benefit from a better understanding of how CFM performs in relation to other policy instruments such as

360 protected areas or industrial logging concessions. Specific contexts need to be considered in designing community forestry interventions, but our results indicate that decision-makers should consider biophysical conditions, community institutional arrangements, and user group characteristics either as predictors of the ability of CFM to deliver on multiple objectives when prioritizing site selections for new CFM interventions, or as indicators of those communities that 365 may require more assistance to overcome unfavorable starting conditions.

\section{Methods}

Our analysis uses data on 643 cases of community forests from 51 countries in Latin America, Africa, and Asia-Pacific regions - where most community forests are located ${ }^{5}$. These data stem 370 from 267 peer-reviewed articles studying social and/or environmental outcomes of community forests, that we selected by systematic review from an initial pool of 15,874 articles. 
Case study selection. Supplementary Figure 1 illustrates the various stages of selection that we used to narrow down the pool of papers to fit our selection criteria (additionally, see ${ }^{18}$ for a 375 published protocol of this review -including criteria used for inclusion of articles- and ${ }^{19}$ for a descriptive overview of the data). We defined community forestry as forest use and governance arrangements under which the rights, responsibilities, and authority for forest management rest, at least in part, with local communities. Due to their diverse cultural and institutional contexts, and the differing perspectives of the many development organization that have supported their emergence, what we refer to today as CFM includes many different types of institutions in which forest users have been acknowledged to have some role in determining how local forests are to be managed. We only included peer-reviewed papers published in English. We also only included cases from Latin America, Africa, and Asia-Pacific regions, where most community forests are located ${ }^{5}$. To be included in our sample, papers had to describe at least one case of a 385 community forest - which we defined as a forest shared by at least three households ${ }^{69}$, and had to report environmental or livelihood indicators of community forests as well as at least one of 50 key contextual variables. Cases may or may not have had some form of endogenous collective management of forests prior to a CFM intervention (32\% of reporting cases did). Environmental indicators included measures of environmental change linked to forest cover, forest condition,

390 and biodiversity, while livelihood indicators included measures of access to forest resources for commercial or subsistence use, and employment, household and community income.

Collectively, these indicators represent key aims of community forest management interventions ${ }^{7,70}$. We excluded cases of afforestation (except enrichment planting) and exotic species plantations to ensure that environmental outcomes were comparable across natural 395 forests. The 50 contextual variables represented key potential sources of variation associated with community forest outcomes. We identified these through a preliminary review of 35 highly cited articles on community forests and forest-cover change ${ }^{19}$. Our goal was to be comprehensive in our use of theories (and related variables) from multiple bodies of literature, to avoid too narrow a focus on institutions (a historical focus of community forestry literature ${ }^{19}$ ) that

400 discounts additional contextual factors, such as biophysical factors, that may play a role in landuse change ${ }^{71}$. The 50 contextual variables included user-group socioeconomic and demographic characteristics, forest- and agriculture-related market factors, institutional factors related to forest 
management, biophysical factors, and factors related to policy changes or specific interventions implemented to support CFM (Supplementary Table 1). Papers could describe multiple

405 community forests, which we treated as separate individual cases. To be included, studies had to have some kind of "comparator" in their research design, whether spatial (control-impact or comparative case studies) and/or temporal (before-after). We sought to broaden the case number beyond the "gold standard" impact assessment designs (which represented $8 \%$ of our cases) to draw from different disciplinary backgrounds that would otherwise be overlooked but that 410 nevertheless document relevant data, and to increase the geographical representation of the conclusions drawn.

The 267 papers that met our selection criteria provided data on an initial set of 697 cases of community forests. Following removal of cases with contradictory outcome variables (see outcome variables below), this number was reduced to a final set of 643 cases from 51 countries 415 that we used for our analyses.

Variable construction and coding. A team of seven researchers performed all data extraction and developed a simple categorical data extraction protocol to maximize standardization across studies. The team went through six data extraction rounds on a subset of randomly selected

420 studies until an acceptable level of intra-team congruence $(\kappa>0.6)$ was reached. With the exception of variables linked to property rights, right bundles (both de jure and de facto rights), input costs, and forest type, all variables where categorized into binary or three-level categorical variables (Supplementary Table 1). In several instances (e.g., slope, elevation, and precipitation), studies reported data as numerical values. In such instances, data were recorded as numerical 425 values and later transformed into categorical values by using tercile values to generate threelevel categorical variables that could be combined with data recorded in categorical formats. Forest classification considered both elevation (e.g. montane forest), latitude (temperate or tropical), and precipitation (dry or humid). We relied on authors' descriptions and use of terms to classify variables. For example, for the variable "type of CFM policy," we classified cases as 430 JFM, PFM, or co-management depending on the language used by the author(s). While JFM and PFM are types of co-management, we use "co-management" to denote a more equitable sharing of power and responsibility between governments and local user groups ${ }^{36}$. If the author(s) did not mention any of these terms, the case was categorized as "other." 
435 Outcome variables. We generated three separate outcome variables combining information on environmental indicators (forest cover, forest condition, and biodiversity), income indicators (community and household income), and resource access rights indicators (commercial access and subsistence access). In all instances, data on individual indicators were extracted as threelevel ordinal variables (decrease, no change, increase) and subsequently combined into single

440 environmental, income, and resource rights outcome variables (Supplementary Figure 2a). Conflicting cases in which indicators within outcomes variables showed opposing trends (e.g., increases in forest condition and decreases in biodiversity) were excluded from the analysis ( $\mathrm{n}=$ 54, Supplementary Figure 2a) but discussed in the main paper to bring attention to the nuances of trade-offs within outcome categories. Instances in which variables combined no change with

445 increases or decreases were classed as either increases or decreases respectively. Our final dataset included 223 cases of joint environmental and income outcomes; 186 cases of joint environmental and access right outcomes; 169 cases of income and access rights outcomes; and 122 cases of triple environmental, income and access rights outcomes (with some articles reporting multiple joint outcomes). For our statistical analysis we generated four separate

450 datasets with no missing data on our outcomes of interest. Joint outcomes were coded as: increases in two dimensions; increase in one dimension and no change in the other; no change in either dimension; decrease in one dimension and no change in the other; increase in one dimension and decrease in the other dimension ("trade-off"); and decreases in both dimensions (Supplementary Figure 2b). We use the term outcome "trade-off" broadly and in the same vein 455 as used elsewhere in the community forestry literature (see ${ }^{2,11,14,72}$ ) where two potentially linked outcomes have an inverse relationship; we posit theoretical, deterministic relationships between some of these joint trade-off outcomes where relevant.

Statistical analysis. In contrast to meta-analyses of clinical experiments, where study designs 460 among studies are often more comparable, the analysis of systematic review data poses inherent challenges due to difference in study designs, and the structure of the extracted dataset. This includes (i) missing data (in our case $53-54 \%$ depending on which outcome variable is considered, Supplementary Figure 3) as well as (ii) a large number of variables (columns) relative to the number of cases (rows) because not all studies collected data for all variables of 
465 interest, and (iii) a large number of categorical variables because information is mainly extracted as nominal or ordinal data.

One approach to deal with these issues would be to conduct multiple bi-variate analyses. However, conducting multiple tests sequentially can lead to type I and II statistical errors (false positives and false negatives, respectively), a serious concern for our analysis given the large

470 number of associations. Another approach to deal with missing data is to remove cases with missing data. However, removing cases with missing data would remove considerable amounts of useful information. Conducting either bi-variate analyses or removing a large number of cases with missing data would also make our analyses susceptible to Simpson's paradox, where associations between variables in different subsets of the data change once subsets are combined.

475 Potential biases could arise either because bi-variate analyses would assess associations among variables with different patterns of missingness (different data subsets), or by affecting factor level combinations among variables if substantial amounts of information are removed.

To address the three issues mentioned above, we expand the methods developed by Oldekop et al. ${ }^{26}$ and develop an analytical algorithm. Our algorithm combines multiple

480 imputations $(\mathrm{N}=100)$ - to generate data subsets with no missing values, with variable selectionto model our joint and triple outcome variables as a function of key subsets of our 50 contextual variables. The variables selected by our algorithm vary in missingness and includes both variables with no missing data, and variables with large amounts of missingness. The patterns of missingness in our data likely reflect the historical focus of interest of CFM studies. To ensure

485 that our approach is not unduly influenced by this pattern we conduct a set of robustness checks on a series of simulated datasets that specifically aim to emulate the patterns of missingness in our dataset (see below). Although our algorithm performs well with up to $90 \%$ missingness in the predictor with the strongest association to the outcome variable, we chose a conservative cutoff for variable inclusion of lower than $85 \%$ in our main analysis.

$490 \quad$ We generated all computer code and conducted all statistical analyses in $R$. Our algorithm first generates a randomly selected sub-sample of our dataset (with replacement); imputes missing data; then selects variables for model inclusion; and subsequently runs a multiple ordinal regression for each sub-sample. In each iteration, we calculated the relative contribution of selected variables to model fit as partial pseudo $R^{2}$ values, as well as individual regression 495 coefficients. We subsequently averaged partial pseudo $R^{2}$ values and regression coefficients for 
the five variables that were most frequently selected in the variable selection step, and calculate standard errors for all regression coefficients. We weighted partial pseudo $R^{2}$ using the proportion of times that individual variables were included in our regression models. We impute data using the rfImpute and select variables using randomForest functions of the randomForest

500 package $^{73}$. These are the values presented in our main analysis. This approach combines the strengths of multiple imputation approaches (e.g., Multiple Imputation by Chained Equations ${ }^{27}$ ), and machine learning algorithms ${ }^{74}$, which perform particularly well for variable selection in instances where datasets contain numerous correlated and interacting predictor variables ${ }^{75}$ (see Supplementary Figure 4 for associations between variables in our dataset). We visually test the

505 proportional odds assumption by adapting Harrell's visual method ${ }^{76}$. An inspection of the generated graphs (Supplementary Figure 9) shows that while a small number of outcome levels overlap for individual variables, for the most part the levels in the outcome are stratified and display similar distances between levels within predictor levels. We interpret this to signify that the proportional odds assumption is largely met in our analysis.

510

Robustness checks. Part of our analysis relies on data imputation. We therefore test the performance of our imputation and analysis algorithm using 16 simulated datasets. These datasets differ in the number of predictor variables (11 and 21 variables), and have varying degrees of missingness (no missing data, 10\%, 25\% and 50\% missingness), as well as varying

515 degrees of missingness in the predictor variable (Predictor 1) with the strongest statistical association to the dependent variable (50\% overall missingness and $25 \%$ missingness in Predictor 1; 50\% overall missingness and 50\% missingness in Predictor 1; and 50\% overall missingness and 90\% missingness in Predictor 1). The missing data maps are shown in Supplementary Figures 5 and 6. These datasets contain 500 rows of data, and like our systematic 520 review datasets, contain three-level categorical variables with varying statistical associations to a three-level ordinal response variable (Supplementary Tables 2 and 3). Because cases from individual studies in our systematic review data have missing data for the same variables, our simulated datasets also include a ten-level blocking variable, which we use to simulate cases and group data rows. To generate $10 \%, 25 \%$ and $50 \%$ missingness levels, we first calculate the

525 number of data cells to be removed relative to of all data cells within our simulated datasets, and then randomly select variables and levels within our blocking variable for removal 
(Supplementary Figure 5).

We then use our algorithm to calculate key statistics relevant to our main analysis (averaged regression coefficients, and inclusion weights - the proportion of times that individual

530 variables are selected and included in the ordinal logistic regression models). Results from our robustness checks suggest that our algorithm and analysis are moderately to strongly robust. As expected, we find that bootstrapped regression coefficients from a run with no missing data are almost identical to those generated by a simple ordinal logistic regression (Supplementary Tables 2 and 3). Critically, we find that averaged coefficients for the top five selected variables for runs with $10 \%, 25 \%$ and $50 \%$ missing data tend to follow the same direction (correspondence in the direction of coefficient $\kappa=0.88$ to 1 , Supplementary Tables 2 and 3, Supplementary Figure 7a,c) and have similar relative magnitudes. This same pattern is reflected in analyses run using datasets with $50 \%$ overall missingness and varying levels of missingness (up to $90 \%$ ) in the predictor showing the strongest statistical association with the outcome variable (correspondence in the direction of coefficient $\kappa=0.53$ to 1 , Supplementary Tables 2 and 3, Supplementary Figure 8a, c).

We also find that variable inclusion weights between runs with no missing data, and missing data are highly correlated $(r=0.82$ to 0.97 , Supplementary Figure $6 \mathrm{~b}, \mathrm{~d})$, suggesting a high degree of overlap in the selection of variables that are included in our models.

\section{Data availability}

The data used for this analysis is available at: http://www.forestlivelihoods.org/resources/. All computer code used in this analysis is available from the authors upon reasonable request.

\section{References}

1. Houghton, R. A., Byers, B. \& Nassikas, A. A. A role for tropical forests in stabilizing atmospheric CO2. Nat. Clim. Chang. 5, 1022-1023 (2015).

2. Newton, P., A Oldekop, J., Brodnig, G., Karna, B. K. \& Agrawal, A. Carbon, biodiversity, and livelihoods in forest commons: synergies, trade-offs, and implications for REDD+. Environ. Res. Lett. 11, 044017 (2016). 
3. Angelsen, A. et al. Environmental Income and Rural Livelihoods: A Global-Comparative Analysis. World Dev. 64, S12-S28 (2014).

4. Lund, J. F., Rutt, R. L. \& Ribot, J. Trends in research on forestry decentralization policies. Curr. Opin. Environ. Sustain. 32, 17-22 (2018).

5. Rights and Resources Initiative. At a Crossroads: Consequential trends in recognition of community-based forest tenure. (2018).

6. Ribot, J. C., Agrawal, A. \& Larson, A. M. Recentralizing While Decentralizing: How National Governments Reappropriate Forest Resources. World Dev. 34, 1864-1886

565 (2006).

7. Charnley, S. \& Poe, M. R. Community Forestry in Theory and Practice: Where Are We Now? Annu. Rev. Anthropol. 36, 301 (2007).

8. Cronkleton, P., Pulhin, J. M. \& Saigal, S. Co-management in community forestry: How the partial devolution of management rights creates challenges for forest communities. Conserv. Soc. 10, 91-102 (2012).

9. Gilmour, D. Forty years of community-based forestry - A review of its extent and effectiveness. (2016).

10. Baynes, J., Herbohn, J., Smith, C., Fisher, R. \& Bray, D. Key factors which influence the success of community forestry in developing countries. Glob. Environ. Chang. 35, 226$575 \quad 238(2015)$.

11. Chhatre, A. \& Agrawal, A. Trade-offs and synergies between carbon storage and livelihood benefits from forest commons. Proc. Natl. Acad. Sci. 106, 17667-17670 (2009).

12. Persha, L., Agrawal, A. \& Chhatre, A. Social and Ecological Synergy: Local Rulemaking, Forest Livelihoods, and Biodiversity Conservation. Science 331, 1606 (2011).

13. Rasolofoson, R. A. et al. Impacts of community forest management on human economic 
well-being across Madagascar. Conserv. Lett. 10, 346-353 (2017).

14. Oldekop, J. A., Sims, K. R. E., Karna, B. K., Whittingham, M. J. \& Agrawal, A. Reductions in deforestation and poverty from decentralized forest management in Nepal. Nat. Sustain. 2, 421-428 (2019).

15. Agrawal, A. \& Benson, C. S. Common property theory and resource governance institutions: strengthening explanations of multiple outcomes. Environ. Conserv. 38, 199$210(2011)$.

16. Larson, A. ., Barry, D. \& Dahal, G. R. New rights for forest-based communities? Understanding processes of forest tenure reform. Int. For. Rev. 12, 78-96 (2010).

17. Hajjar, R., Kozak, R. A. \& Innes, J. L. Is decentralization leading to 'real' decisionmaking power for forest-dependent communities? Case studies from Mexico and Brazil. Ecol. Soc. 17, (2012).

18. Newton, P. et al. What are the biophysical, institutional, and socioeconomic contextual 595 factors associated with improvements in livelihood and environmental outcomes in forests managed by communities? A systematic review protocol. Work. Pap. 9 (2015). doi:10.17528/cifor/005494

19. Hajjar, R. et al. The data not collected on community forestry. Conserv. Biol. 30, 13571362 (2016).

600 20. Vyamana, V. . Participatory forest management in the Eastern Arc Mountains of Tanzania: who benefits? Int. For. Rev. 11, 239-253 (2009).

21. Mohammed, A. J. \& Inoue, M. Forest-dependent communities' livelihood in decentralized forest governance policy epoch: case study from West Shoa zone, Ethiopia. J. Nat. Resour. Policy Res. 5, 49-66 (2013).

605 22. Nielsen, M. Improving the conservation status of the Udzungwa Mountains, Tanzania? The effect of joint forest management on bushmeat hunting in the Kilombero nature reserve. Conserv. Soc. 9, 106 (2011). 
23. Gobeze, T., Bekele, M., Lemenih, M. \& Kassa, H. Participatory forest management and its impacts on livelihoods and forest status: the case of Bonga forest in Ethiopia. Int. For. Rev. 11, 346-358 (2009).

24. Mishra, T., Mandal, D. \& Maiti, S. Evaluation of regeneration of Shorea robusta forests under joint forest management in West Bengal, India. Int. J. Environ. Sustain. Dev. 5, 12 22 (2006).

25. Oyono, P., Samba, S. \& Biyong, M. Beyond the decade of policy and community euphoria: The state of livelihoods under new local rights to forest in rural Cameroon. Conserv. Soc. 10, 173 (2012).

26. Oldekop, J. A., Holmes, G., Harris, W. E. \& Evans, K. L. A global assessment of the social and conservation outcomes of protected areas. Conserv. Biol. 30, 133-141 (2016).

27. White, I., Royston, P. \& Wood, A. Multiple imputation by chained equations: issues and guidance for practice. 30(4): 377-399. Stat. Med. 30, 377-399 (2011).

28. Leuschner, C., Moser, G., Bertsch, C., Röderstein, M. \& Hertel, D. Large altitudinal increase in tree root/shoot ratio in tropical mountain forests of Ecuador. Basic Appl. Ecol. 8, 219-230 (2007).

29. Thanichanon, P., Schmidt-Vogt, D., Messerli, P., Heinimann, A. \& Epprecht, M. Secondary Forests and Local Livelihoods along a Gradient of Accessibility: A Case Study in Northern Laos. Soc. Nat. Resour. 26, 1283-1299 (2013).

30. Schlager, E. \& Ostrom, E. Property-Rights Regimes and Natural Resources : A Conceptual Analysis. Land Econ. 68, 249-262 (1992).

31. Place, F. \& Hazell, P. Productivity Effects of Indigenous Land Tenure Systems in SubSaharan Africa. Am. J. Agric. Econ. 75, 10-19 (1993).

32. Gibson, C., Lehoucq, F. \& Williams, J. Does Privatization Protect Natural Resources? Property Rights and Forests in Guatemala. Soc. Sci. Q. 83, 206-225 (2002). 
33. Bugri, J. T. The dynamics of tenure security, agricultural production and environmental degradation in Africa: Evidence from stakeholders in north-east Ghana. Land use policy 25, 271-285 (2008).

34. Cronkleton, P. \& Larson, A. Formalization and Collective Appropriation of Space on Forest Frontiers: Comparing Communal and Individual Property Systems in the Peruvian and Ecuadoran Amazon. Soc. Nat. Resour. 28, 496-512 (2015).

35. Nayak, P. K. \& Berkes, F. Politics of co-optation: Community forest management versus joint forest management in Orissa, India. Environ. Manage. 41, 707-718 (2008).

36. Berkes, F., George, P. \& Preston, R. J. Co-management: the evolution in theory and practice of the joint administration of living resources. Alternatives 18, 12-18 (1991).

37. Humphries, S., Holmes, T., de Andrade, D. F. C., McGrath, D. \& Dantas, J. B. Searching for win-win forest outcomes: Learning-by-doing, financial viability, and income growth for a community-based forest management cooperative in the Brazilian Amazon. World Dev. (2018). doi:10.1016/j.worlddev.2018.06.005

38. Bray, D. B. et al. Mexico's community-managed forests as a global model for sustainable landscapes. Conserv. Biol. 17, 672-677 (2003).

39. Balooni, K. \& Pulhin, J. When is Decentralization in Forest Management a Success and 650 when is it a Failure?: Case Studies from the Philippines. Order A J. Theory Ordered Sets Its Appl. 1-18 (2007).

40. Oldekop, J. A., Bebbington, A. J., Brockington, D. \& Preziosi, R. F. Understanding the Lessons and Limitations of Conservation and Development. Conserv. Biol. 24, 461-469 (2010).

655 41. Rudel, T. K. et al. Forest transitions: Towards a global understanding of land use change. Glob. Environ. Chang. 15, 23-31 (2005).

42. Erbaugh, J. T. \& Oldekop, J. A. Forest landscape restoration for livelihoods and wellbeing. Curr. Opin. Environ. Sustain. 32, 76-83 (2018). 
43. Honey-Rosés, J., Maurer, M., Ramírez, M. I. \& Corbera, E. Quantifying active and 660 passive restoration in Central Mexico from 1986-2012: assessing the evidence of a forest transition. Restor. Ecol. 26, 1180-1189 (2018).

44. Oldekop, J. A., Sims, K. R. E., Whittingham, M. J. \& Agrawal, A. An upside to globalization: International outmigration drives reforestation in Nepal. Glob. Environ. Chang. 52, 66-74 (2018).

665 45. Peluso, N. L. \& Purwanto, A. B. The remittance forest: Turning mobile labor into agrarian capital. Singap. J. Trop. Geogr. 39, 6-36 (2018).

46. Sikor, T. \& Nguyen, T. Q. Why May Forest Devolution Not Benefit the Rural Poor? Forest Entitlements in Vietnam's Central Highlands. World Dev. 35, 2010-2025 (2007).

47. Pulhin, J. M. \& Dressler, W. H. People, power and timber: The politics of communitybased forest management. J. Environ. Manage. 91, 206-214 (2009).

48. Jones, J. P. G. et al. Human migration to the forest frontier: Implications for land use change and conservation management. Geo Geogr. Environ. 5, (2018).

49. Robson, J. P. \& Berkes, F. Exploring some of the myths of land use change: Can rural to urban migration drive declines in biodiversity? Glob. Environ. Chang. 21, 844-854 (2011).

50. Lambin, E. F. \& Meyfroidt, P. Global land use change, economic globalization, and the looming land scarcity. Proc. Natl. Acad. Sci. U. S. A. 108, 3465-3472 (2011).

51. Scherr, S. J., White, a. \& Kaimowitz, D. Making markets work for forest communities. Int. For. Rev. 5, 67-73 (2003).

680 52. Brooks, J. S., Waylen, K. A. \& Borgerhoff Mulder, M. How national context, project design, and local community characteristics influence success in community-based conservation projects. Proc. Natl. Acad. Sci. 109, 21265-21270 (2012).

53. Larson, A. M. \& Soto, F. Decentralization of Natural Resource Governance Regimes. 
Annu. Rev. Environ. Resour 33, 213-39 (2008).

685 54. Anderson, J., Mehta, S., Epelu, E. \& Cohen, B. Managing leftovers: Does community forestry increase secure and equitable access to valuable resources for the rural poor? For. Policy Econ. 58, 47-55 (2015).

55. Thanh, T. N. \& Sikor, T. From legal acts to actual powers: Devolution and property rights in the Central Highlands of Vietnam. For. Policy Econ. 8, 397-408 (2006).

690 56. Larson, A. M., Cronkleton, P., Barry, D. \& Pacheco, P. Tenure rights and beyond: Community access to forest resources in Latin America. (CIFOR, 2008).

57. Scheba, A. \& Mustalahti, I. Rethinking 'expert' knowledge in community forest management in Tanzania. For. POLICY Econ. 60, 7-18 (2015).

58. Ameha, A., Nielsen, O. J. \& Larsen, H. O. Impacts of access and benefit sharing on livelihoods and forest: Case of participatory forest management in Ethiopia. Ecol. Econ. 97, 162-171 (2014).

59. Lescuyer, G. Sustainable forest management at the local scale: A comparative analysis of community forests and domestic forests in Cameroon'. Small-scale For. 12, 51-66 (2013).

60. Guiang, E. S. \& Castillo, G. E. M. Trends in forest ownership, forest resources tenure and institutional arragenments in the Philippines: Are they contributing to better forest management and poverty reduction? in Understanding forest tenure in South and Southeast Asia. Forestry Policy and Institutions Working paper No. 14 (FAO, 2007).

61. Blackman, A., Corral, L., Lima, E. S. \& Asner, G. P. Titling indigenous communities protects forests in the Peruvian Amazon. Proc. Natl. Acad. Sci. 114, 4123-4128 (2017).

705 62. Sikor, T. et al. Community forestry in Asia and the Pacific: Pathway to inclusive development. (2013).

63. Wren-lewis, L., Becerra-valbuena, L. \& Houngbedji, K. Formalizing land rights can reduce forest loss: Experimental evidence from Benin. Sci. Adv. 6, 1-9 (2020). 
64. Ostrom, E. Analzying long-enduring, self-organized, and self-governed CPRs. in Governing the Commons: the Evolution of Institutions for Collective Action. (Cambridge University Press, 1990).

65. Varughese, G. \& Ostrom, E. The contested role of heterogeneity in collective action: Some evidence from community forestry in Nepal. World Dev. 29, 747-765 (2001).

66. Agrawal, A. Forests, governance, and sustainability: common property theory and its contributions. Int. J. Commons 1, 111-136 (2007).

67. Pagdee, A., Kim, Y. \& Daugherty, P. J. What Makes Community Forest Management Successful: A Meta-Study From Community Forests Throughout the World. Soc. Nat. Resour. 19, 33-52 (2006).

68. Hajjar, R. \& Oldekop, J. A. Research frontiers in community forest management. Curr. Opin. Environ. Sustain. 32, 119-125 (2018).

69. IFRI. International Forestry Resources and Institutions (IFRI) network: research methods. Available from: www.ifriresearch.net. (2013).

70. Persha, L., Fischer, H., Chhatre, A., Agrawal, A. \& Benson, C. Biodiversity conservation and livelihoods in human-dominated landscapes: Forest commons in South Asia. Biol. Conserv. 143, 2918-2925 (2010).

71. Geist, H. J. \& Lambin, E. F. Proximate Causes and Underlying Driving Forces of Tropical Deforestation. Bioscience 52, 143 (2002).

72. Rana, E., Thwaites, R. \& Luck, G. Trade-offs and synergies between carbon, forest diversity and forest products in Nepal community forests. Environ. Conserv. 44, 5-13 (2017).

73. Liaw, A. \& Wiener, M. Package 'randomForest'. The Comprehensive R Archive Network. (2018).

74. Breiman, L. Random Forests. Mach. Learn. 45, 5-32 (2001). 
75. Genuer, R., Poggi, J. \& Tuleau-Malot, C. Variable selection using random forests. Pattern Recognit. Lett. 31, 2225-2236 (2010).

76. Harrell, F. Regression Modelling Strategies. (Springer, 2015).

Correspondence and requests for materials should be addressed to R.H.

\section{Acknowledgements}

We thank the Evidence Based Forestry Initiative at the Centre for International Forestry Research (CIFOR) and the U.K. Department for International Development (DfID) for financing this research through its KNOWFOR program grant. J.A.O. was supported through an EU FP7 Marie Curie Fellowship (FORCONEPAL). P.C. was supported through the CGIAR Research

745 Program on Forest, Trees and Agroforestry (FTA), led by CIFOR. We also thank M. Vikas, M. Burbidge, A. Langeland, and K. Gregory for their help in screening papers and extracting data, and G. Steward, M. Grainger, M. Whittingham, R. Preziosi, and E.W. Harris for their help with the statistical analysis.

\section{Author contributions}

750 R.H., J.A.O., P.N., A.J.R. and W.Z. conceived and designed the systematic review. R.H., J.A.O., and W.Z. conducted the review and data extraction. R.H. and J.A.O. conducted the analysis and drafted the manuscript. R.H., J.A.O., P.C., P.N., A.J.R. and W.Z. contributed to results interpretation and finalizing of the paper.

\section{Competing interests}

755 The authors declare no competing interests. 


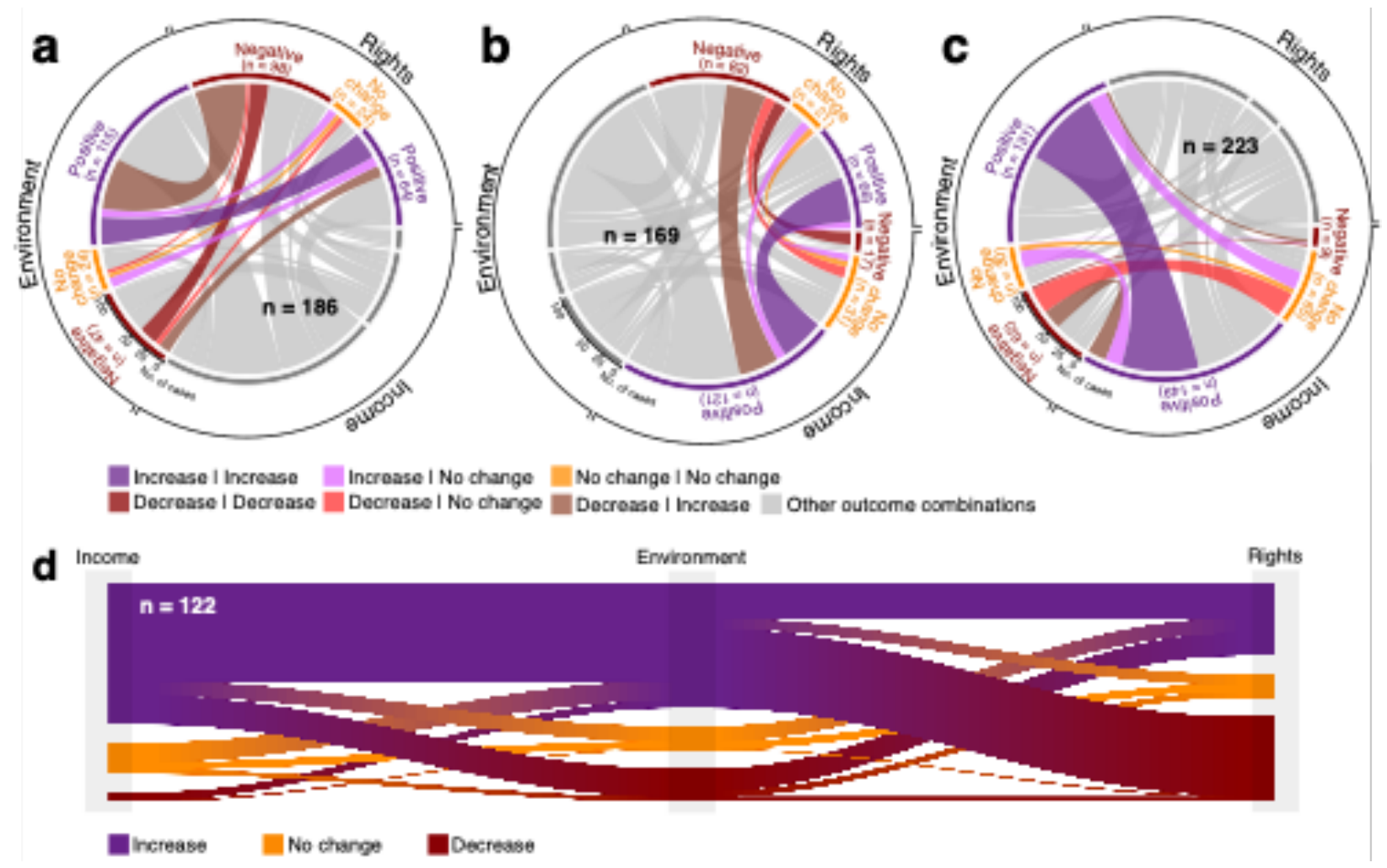

Figure 1. Double and triple outcomes of social and environmental outcomes: (a) Environment and rights; (b) income and rights; (c) environment and income; and (d) income, environment, and rights. Studies examining resource rights and forest environmental condition outcomes reported joint positive outcomes in $45 \%$ of cases (dark purple) and studies examining income and access rights reported joint positive outcomes in $34 \%$ of cases. Studies examining income and forest environmental conditions reported joint positive outcomes in $46 \%$ of cases while studies examining all three outcomes reported positive outcomes across all three dimensions in $18 \%$ of cases. 

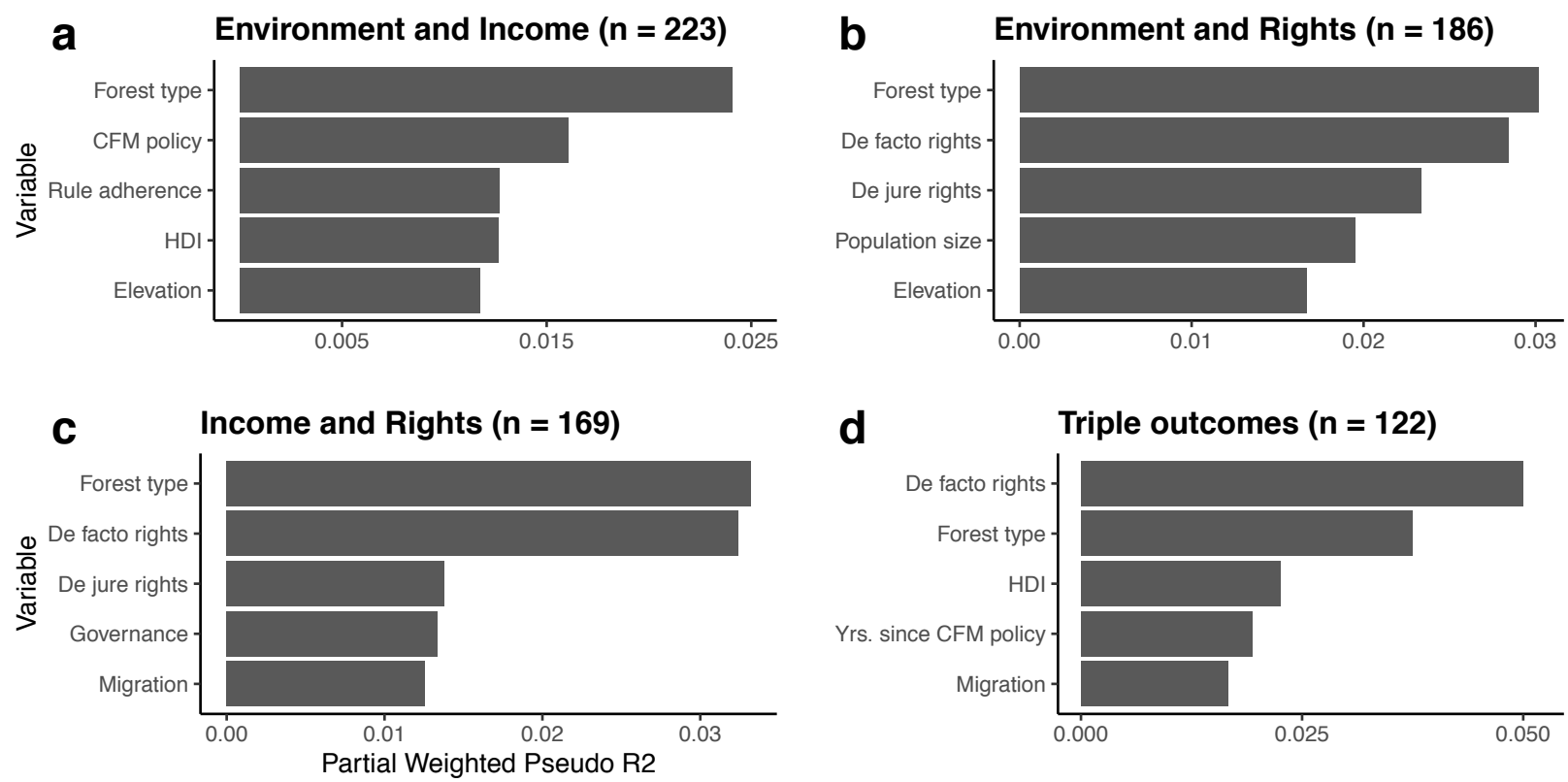

Figure 2. Mean partial weighted pseudo R2 values for the five most frequently selected variables predicting positive social and environmental outcomes of community forestry across multiple dimensions. Most of the variation explaining social and environmental outcomes in our models was explained by a mixture of forest biophysical characteristics and socio-economic factors. 

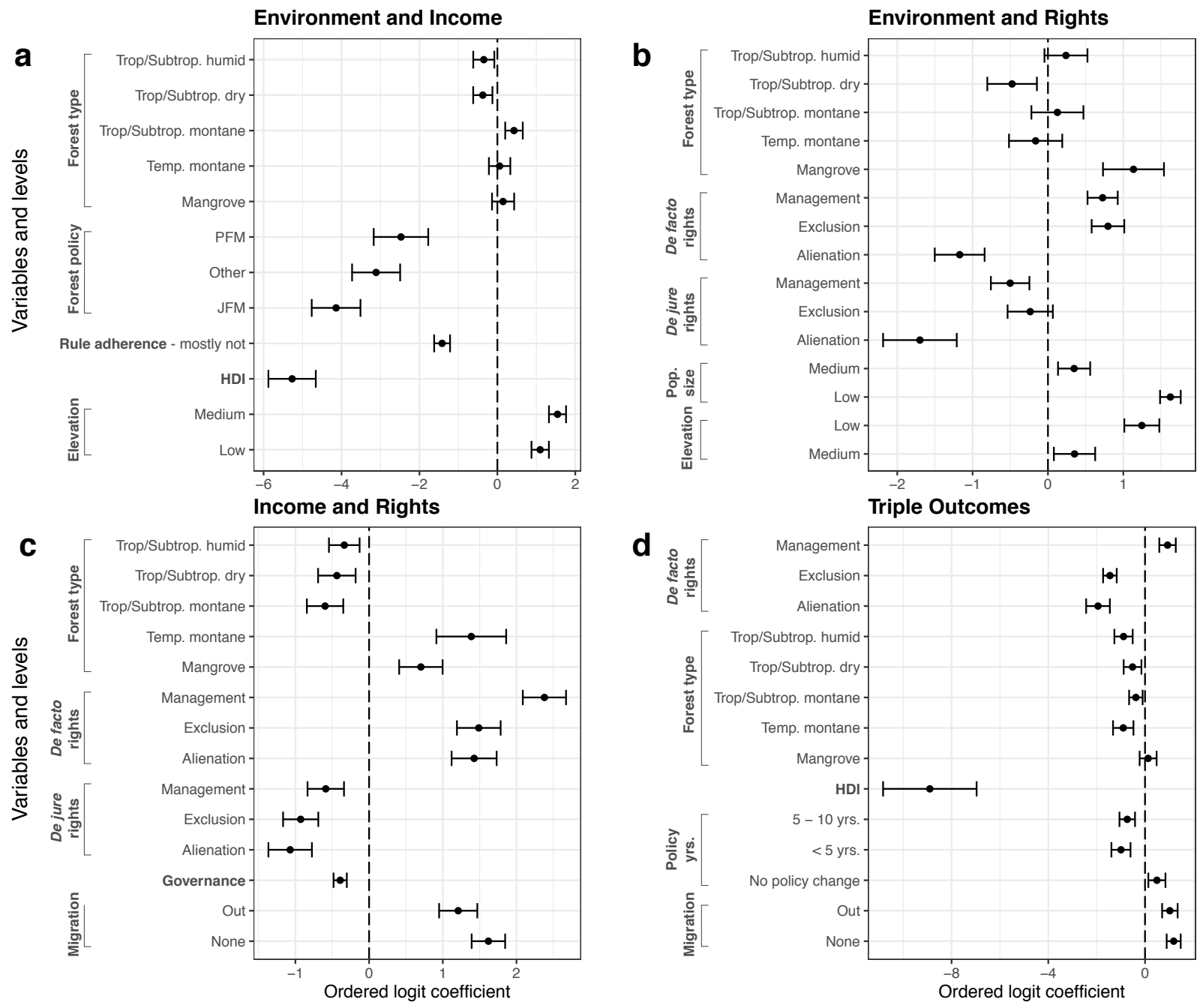

Figure 3. Mean regression coefficients of the five most frequently selected variables explaining social and environmental outcomes of community forestry in our models. Error bars represent the standard error of the mean coefficient value. The reference levels are: for forest type, "Temperate dry;" for forest policy, "Co-management;" for rule adherence, "Mostly follow;" for elevation, "High;" for de facto and de jure rights, "Access and withdrawal;" for population size, "High;" for migration, "In-migration;" for policy years ">10yrs." Governance and HDI are continuous measures and thus do not have reference levels. 
